Anuario de la Facultad de Derecho. Universidad de Extremadura 36 (2020): 947-956 ISSN: 0213-988X - ISSN-e: 2695-7728

\title{
SELECCIÓN Y COMENTARIO DE RESOLUCIONES DEL ORDEN JURISDICCIONAL PENAL. AUDIENCIAS PROVINCIALES DE CÁCERES Y BADAJOZ. AÑO 2020
}

\begin{abstract}
SELECTION AND COMMENTARY ON CRIMINAL COURT DECISIONS. PROVINCIAL COURTS OF CÁCERES AND BADAJOZ. YEAR 2020
\end{abstract}

\section{MARía Félix Tena ARAgón} Tribunal Superior de Justicia de Extremadura

Recibido: 02/01/2021 Aceptado: 28/01/2021

\section{RESUMEN}

Se ha llevado a cabo una selección de las resoluciones judiciales más representativas y relevantes dictadas por las Audiencias Provinciales extremeñas de Cáceres y Badajoz durante el año natural 2020. Dichas resoluciones corresponden al orden jurisdiccional Penal. Estas sentencias seleccionadas han sido objeto de comentario, dentro del contexto jurídico que las ha generado, por una destacada magistrada especializada en dicho orden jurisdiccional.

Palabras clave: Resoluciones judiciales, orden jurisdiccional Penal, Audiencia, comentarios jurídicos.

\section{ABSTRACT}

A selection of the most representative and relevant judicial resolutions issued by the Extremadura Provincial Courts of Cáceres and Badajoz has been carried out during the 
2020 calendar year. Said resolutions correspond to the Criminal jurisdictional order. These selected judgments have been the subject of comment, within the legal context that generated them, by a prominent magistrate specialized in said jurisdictional order.

Keywords: Judicial resolutions, Criminal jurisdictional order, Court, legal comments.

\section{SENTENCIA No 44/2020 DE 7 DE FEBRERO. AUDIENCIA PROVINCIAL DE CÁCERES, SECCIÓN $2^{\mathrm{a}}$.}

Concepto de "patinete eléctrico" a los efectos de apreciar los requisitos administrativos para su circulación.

El Reglamento (UE) no 168/2013 del Parlamento Europeo y del Consejo de 15 de enero de 2013 relativo a la homologación de los vehículos de dos o tres ruedas y los cuatriciclos, y a la vigilancia del mercado de dichos vehículos distingue en su artículo 4, relativo a las categorías de vehículos, dentro de los vehículos de categoría L1e (vehículo de motor de dos ruedas ligero) dos subcategorías, los vehículos tipo L1e-A (a los que denomina "ciclo de motor"), y los vehículos tipo L1e-B (denominados "ciclomotor de dos ruedas"). Descripción de unos y otros. Los vehículos tipo L1e-B quedan, a día de hoy, sometidos a las normas que rigen la utilización de los ciclomotores. No todos los "patinetes eléctricos" entran en la categoría de Vehículo de Movilidad Personal (VMP), y pueden ser considerados vehículos L1e-B siendo necesaria la autorización administrativa correspondiente para su conducción.

SENTENCIA No 77/2020 DE 12 DE MARZO. AUDIENCIA PROVINCIAL DE CÁCERES, SECCIÓN $2^{\mathrm{a}}$.

Juicio oral penal. Orden en la práctica de la prueba. Declaración de los acusados. Límite temporal de los informes finales de las partes y de la última palabra a los acusados.

La denegación de la alteración del orden por parte de la juzgadora de instancia se hizo en una resolución oral razonada, sobre la base de unos 
argumentos que no eran arbitrarios, sin que esté de más recordar que los acusados tenían en cualquier caso derecho a no declarar en ese momento inicial, como también lo tienen a la última palabra, pudiendo en ese postrer momento, en el que ya conocen el resultado de toda la prueba practicada, exponer a la juzgadora todas aquellas cuestiones que pudieran resultar de interés para su defensa, derecho a la última palabra que, obvio es decirlo, pueden llevar a efecto previo asesoramiento de su letrado, pues en cualquier momento todo acusado puede solicitar comunicarse con su asistente legal, lo que garantiza debidamente el pleno ejercicio de su derecho a la defensa.

Limitar temporalmente los informes no implica de forma automática una vulneración del derecho a la defensa, tal vulneración únicamente podría apreciarse cuando quedara debidamente justificado que esa limitación temporal ha causado una efectiva indefensión material a la parte, por ser el tiempo concedido por la juzgadora razonablemente insuficiente, desde un punto de vista objetivo, para el adecuado ejercicio de ese derecho de defensa, justificación de una indefensión material que no se acomete argumentalmente en el recurso. En igual situación se encuentra el uso, por parte de los acusados, del derecho a la última palabra.

SENTENCIA No ${ }^{\circ}$ 140/2020 DE 9 DE OCTUBRE. AUDIENCIA PROVINCIAL DE BADAJOZ, SECCIÓN $3^{\mathrm{a}}$.

Normas específicas en el procedimiento por delito leve.

La ilustración de los derechos de la denunciada ex art. 118 LECrim no resulta obligatoria en el marco de un procedimiento por delito leve, en el que la tramitación consiste en la citación a un juicio verbal o vista, sin que necesariamente deba preceder una declaración del denunciado como investigado, ni siquiera existe una fase de instrucción propiamente dicha. Tampoco en aplicación el art. 962 LECrim en cuanto a la información escrita que ha de darse a la parte denunciada, por cuanto se refiere tal precepto a los supuestos de delito leve con 
citación policial al juicio, cuando ha sido el Juzgado el que ha procedido a la citación tras la pertinente incoación del procedimiento art 967 LECrim.

SENTENCIA No $35 / 2020$ DE 13 DE OCTUBRE. AUDIENCIA PROVINCIAL DE BADAJOZ, SECCIÓN $1^{\mathrm{a}}$.

Delito leve de vejaciones en el ámbito de violencia de género.

El dato de que se denuncie tarde (o no inmediatamente) no significa que los hechos denunciados no sean ciertos. Pensar lo contrario es un prejuicio de género y es evidente que no cabe introducir o aplicar prejuicios de género en el ámbito del enjuiciamiento de este tipo de delitos, pues así viene determinado en el artículo 4 de la ley orgánica para la igualdad efectiva de mujeres y hombres, LO 3/2007, de 22 de marzo, toda vez que tras esta ley la igualdad de género es un principio informador del ordenamiento jurídico y ha de observarse en la interpretación y aplicación de las normas jurídicas. La pena de prohibición de aproximación a la víctima no es desproporcionada, no se trata de una medida cautelar que se adopta en el curso de la instrucción de un procedimiento sobre la base de meros indicios, sino que la pena de prohibición de aproximación se impone en sentencia, tras la celebración del juicio, y una vez constatada y probada con la debida certeza la comisión de un delito.

SENTENCIA No 142/2020 DE 14 DE OCTUBRE. AUDIENCIA PROVINCIAL DE BADAJOZ, SECCIÓN $3^{\mathrm{a}}$.

Asistencia letrada en delitos leves. Momento procesal para su petición. La ausencia de asistencia letrada no siempre conlleva nulidad de actuaciones en este tipo de delitos.

Quien alegue indefensión como consecuencia de la vulneración del derecho a la asistencia de letrado, no ha de haber provocado dicha situación con su falta de diligencia, así como que dicha indefensión debe ser real y efectiva; de forma que la situación de indefensión generada por la falta de defensa técnica no 
resulte ser consecuencia directa del proceder de la parte y además la autodefensa del litigante debe haberse revelado como insuficiente y perjudicial para el mismo, impidiéndole articular una protección adecuada de sus derechos e intereses legítimos en el proceso. El denunciado conocía su derecho de ser asistido de abogado, de libre designación o de oficio. No consta petición de designación antes de la vista, y tampoco al comienzo de esta como se alega, sino solo cuando se comienza el interrogatorio del denunciado.

SENTENCIA No ${ }^{\circ}$ 43/2020 DE 16 DE OCTUBRE. AUDIENCIA PROVINCIAL DE BADAJOZ, SECCIÓN $3^{\mathrm{a}}$.

Concepto de "circulación de vehículos" para garantizar la cobertura por el seguro de responsabilidad civil del automóvil.

Directiva 2009/103/CE del Parlamento Europeo y del Consejo, de 16 de septiembre de 2009, relativa al seguro de la responsabilidad civil que resulta de la circulación de vehículos automóviles, así como al control de la obligación de asegurar esta responsabilidad. Jurisprudencia del TJUE al respecto, el concepto de «circulación de vehículos» que figura en la Directiva no se limita a las situaciones de circulación vial e incluye cualquier utilización de un vehículo que sea conforme con su función habitual, concretamente toda utilización del vehículo como medio de transporte. No depende de las características del terreno en el que se utilice el vehículo ni, en particular, del hecho de que esté inmovilizado en un aparcamiento en el momento de producirse el accidente. En estas circunstancias, el TJUE considera que el estacionamiento y el período de inmovilización del vehículo son estadios naturales y necesarios que forman parte integrante de su utilización como medio de transporte.

Estas conclusiones fueron recogidas por la STS 3983/2019 de fecha 17-XII2019 dado el carácter vinculante de la jurisprudencia del TJUE (art. 4 bis LOPJ) y por la STS 1310/2020 de fecha 26-V-2020, en el caso de vehículo empleado como si se tratara de un arma, para la ejecución de un hecho doloso, y circulando por la acera, lo calificó como hecho de la circulación. 
SENTENCIA No $145 / 2020$ DE 20 DE OCTUBRE. AUDIENCIA PROVINCIAL DE BADAJOZ, SECCIÓN $3^{\mathrm{a}}$.

Delito de organización criminal. Distinción entre organización y grupo criminal.

La organización criminal requiere un carácter estable o su constitución o funcionamiento por tiempo indefinido, y que de manera concertada y coordinada se repartan las tareas o funciones entre sus miembros con aquella finalidad, exige de una estructura más compleja, de un plus, y el grupo criminal, sin embargo, puede apreciarse aunque no concurra ninguno de estos dos requisitos, o cuando concurra solo uno de ellos, debilita el presupuesto de la estabilidad por la exigencia de una relativa permanencia -formación no fortuita- y una estructura mucho más elemental para hacer realidad la actuación concertada de sus integrantes, sin necesidad de una asignación formal de funciones. El grupo criminal tiene un carácter residual, el concepto de grupo criminal se crea sobre los conceptos negativos de no concurrencia de alguna o algunas de las características de la organización criminal, de modo que basta la no concurrencia de uno de los elementos estructurales del tipo de organización delictiva, para que surja la figura de grupo criminal. En nada afecta a la calificación de integración en organización o grupo criminal el hecho de que no participen todos sus integrantes en los distintos hechos delictivos cometidos por la organización o el grupo, incluso si algunos de ellos solo intervinieron en uno de ellos, pues la organización o el grupo es la estructuración de una forma de delinquir al que es ajena la concreta situación del que solo intervino en un hecho, pero lo hizo en el grupo en el que se integró.

SENTENCIA No 150/2020 DE 26 DE OCTUBRE. AUDIENCIA PROVINCIAL DE BADAJOZ, SECCIÓN $3^{\mathrm{a}}$.

Delito de usurpación de inmuebles en su modalidad no violenta del núm. 2 del art. 245 CP.

Se analiza los requisitos que han de concurrir en el delito para dar cobertura penal específica a la ocupación de viviendas o edificios en contra de la voluntad 
de sus propietarios o poseedores. la protección penal respecto a la propiedad inmobiliaria, a salvo los supuestos de abandono, absoluta dejación o respecto de inmuebles en estado de ruina, es verificable en relación a cualquier inmueble, no sólo se contrae a la ocupación de viviendas sino a la de inmuebles y edificaciones que no constituyan morada, y por tanto sin que sea exigible que su titular ostente una detentación material entendida como algún tipo de uso del mismo, más allá de la efectiva constatación de una voluntad de exclusión que no requiere más exigencia que la de mantener el inmueble cerrado y en condiciones de habitabilidad, lo que ha de entenderse como buen estado general de uso para el fin que le resulte propio, obviando reformas puntuales o la falta transitoria de servicios de electricidad y abastecimiento de agua. Ocupar no es sólo instalarse en un espacio para residir en él con carácter permanente, sino también tomar posesión, entrando en un lugar, y usando de él, solo hay ocupación cuando la posesión se detenta con cierta vocación de permanencia y no cuando es puntual.

SENTENCIA No 247/2020 DE 30 DE OCTUBRE. AUDIENCIA PROVINCIAL DE CÁCERES, SECCIÓN $2^{\mathrm{a}}$.

Delitos contra el patrimonio. Administración desleal y apropiación indebida.

El vigente delito del art. 252 del Código Penal, delimita sus diferencias con la apropiación indebida que ahora se regula en el art. 253 del mismo cuerpo legal exclusivamente en cuanto al destino del dinero, pues en el caso de la apropiación es el patrimonio del autor y en el caso de la gestión desleal son otros destinos que no tienen por qué ser particulares del sujeto activo, en tanto en cuanto no precisa un ánimo de lucro que va ínsito en el hecho de hacer propio lo que no lo es.

SENTENCIA No 264/2020 DE 13 DE NOVIEMBRE. AUDIENCIA PROVINCIAL DE CÁCERES, SECCIÓN $2^{\mathrm{a}}$.

Impago de pensiones. Delito permanente. Consecuencias sobre el ámbito temporal en relación con la responsabilidad civil. Prueba en segunda instancia. Nulidad de la sentencia absolutoria al no haber tenido en consideración 
prueba practicada en segunda instancia, aunque no lo hubiera pedido expresamente la apelante.

El delito se consuma cuando no se paguen dos pensiones mensuales seguidas o cuatro alternas, pero sus efectos penales se mantienen mientras duren los impagos. Se produce, pues, un único delito permanente, cuyo momento final tiene lugar tras la cesación ininterrumpida de la lesión al bien jurídico o el enjuiciamiento de la conducta lesiva. El ámbito temporal de los procesos penales tramitados por el delito tipificado en el art. 227 del Código Penal comprenderá, como regla general, el período que abarca desde el primer incumplimiento hasta la fecha del juicio oral, constituyendo el objeto de cada proceso concreto, los reiterados incumplimientos -consecutivos o alternos- constatados hasta dicho momento procesal.

No pudieron tenerse en cuenta en la instancia los elementos documentales que luego se aportaron y han sido admitidos en la alzada. Nos encontramos ante pruebas relevantes, directamente relacionadas con el ámbito objetivo de la infracción denunciada. El derecho a la tutela judicial efectiva impetrado por la acusación se habría visto necesariamente afectado al no haber podido el Juzgador a quo entrar a valorar ese material que, presentado ahora en segunda instancia, fue finalmente admitido.

No cabe revocar en apelación las sentencias absolutorias dictadas en las causas en las que la práctica de la prueba depende en gran medida de los principios que inspiran a la jurisdicción penal. No puede la Sala de apelación ex novo dictar una segunda sentencia condenatoria en base a una errónea valoración de la prueba; pero sí estaría facultada a declarar la nulidad de la Sentencia dictada y devolver la causa al Juzgado de origen para un nuevo enjuiciamiento.

SENTENCIA No 266/2020 DE 13 DE NOVIEMBRE. AUDIENCIA PROVINCIAL DE CÁCERES, SECCIÓN $2^{\mathrm{a}}$.

Delito de malversación de caudales públicos. Actual regulación y concepto. Delito continuado de malversación en concurso medial con un delito 
continuado de fraude. Delimitación de los elementos de los delitos de prevaricación, administración desleal y fraude.

La reforma operada en el Código Penal por la Ley Orgánica 1/2015 supuso, entra otras novedades, una modificación sustancial del delito de malversación de caudales públicos. Tal y como indicaba la reforma en su preámbulo, la malversación se mantenía históricamente en nuestro Derecho Penal básicamente referida a supuestos de sustracción de los fondos públicos y, en mucha menor medida, a la posible desviación del destino de los mismos; "la reforma introduce una nueva tipificación de la malversación como un supuesto de administración desleal de fondos públicos. De este modo se incluyen dentro del ámbito de la norma, junto con las conductas de desviación y sustracción de los fondos públicos, otros supuestos de gestión desleal con perjuicio para el patrimonio público”.

SENTENCIA No $279 / 2020$ DE 27 DE NOVIEMBRE. AUDIENCIA PROVINCIAL DE CÁCERES, SECCIÓN $2^{\mathrm{a}}$.

Agravante de parentesco en los delitos de violencia de género. Agravante de discriminación por razón de género.

El parentesco que concurre en los delitos de violencia física y psíquica habitual, lesiones en el ámbito familiar y vejaciones injustas de carácter leve, si a la vez se produce entre cónyuge o persona que esté o haya estado ligada al autor por una análoga relación de afectividad aun sin convivencia que constituye un elemento objetivo del tipo, excluye el efecto de esa circunstancia en la individualización de la pena conforme dispone el artículo 67 del Código Penal.

Cuando se acredita que las razones de género afectan a delitos que entre sus elementos ya recogen el que la víctima es cónyuge o persona que esté o haya estado ligada al autor por una análoga relación de afectividad aun sin convivencia, cabría plantearse si la agravante de discriminación por razón de género resulta aplicable o si, por el contrario, en los delitos de violencia de género la agravación que nos ocupa debe entenderse ínsita en el tipo penal y, por tanto, resultar de aplicación la regla del artículo 67 del Código Penal evitando incurrir 
en un bis in ídem. Estos delitos no incluyen ni exigen entre sus elementos una prueba del ánimo de dominar o de machismo del hombre hacia la mujer, sino el comportamiento objetivo de la agresión, no es un elemento del tipo desde el punto de vista estrictamente técnico jurídico. Cuando se dé el dato objetivo del vínculo, la acción típica (la agresión sin lesión, la violencia habitual, los insultos y vejaciones) determinará la comisión de la infracción. Si además se acredita que la acción típica viene "motivada por razones de género", deberá apreciarse la circunstancia agravante prevista en el artículo 22.4 del Código Penal.

María Félix Tena Aragón

Presidencia

Tribunal Superior de Justicia de Extremadura mf.tena@poderjudicial.es https://orcid.org/oooo-0002-5111-9699 